\title{
TRADUÇÃO E INTERPRETAÇÃO AUDIOVISUAL DA LÍNGUA DE SINAIS (TIALS) NO BRASIL: UM ESTUDO DE RECEPÇÃO SOBRE AS JANELAS DE LIBRAS NA COMUNIDADE SURDA
}

\author{
Vinícius Nascimento 1 \\ ${ }_{1}^{1}$ Universidade Federal de São Carlos, São Carlos, São Paulo, Brasil
}

\begin{abstract}
Resumo: Neste $\operatorname{artigo~}^{1}$, são apresentados os resultados de uma pesquisa de amplitude nacional que objetivou compreender a preferência dos surdos em relação às janelas de Libras, que constituem o espaço de circulação da tradução e da interpretação da língua de sinais em obras audiovisuais. Os dados foram coletados por meio de um questionário virtual bilíngue que circulou entre a comunidade surda brasileira por meio das redes sociais apresentando aos respondentes surdos cinco propostas de janelas para três gêneros audiovisuais: cinematográfico-comédia, jornalístico-televisivo e videoaula. Os respondentes avaliaram cada proposta com notas entre 1 (ruim) e 5 (excelente). Os dados mostram que a preferência pelas janelas se altera de acordo com o gênero avaliado. As mesmas propostas receberam diferentes avaliações nos três gêneros e as propostas oficiais não foram bem aceitas para os gêneros no qual elas foram criadas. As janelas elaboradas pelo mercado receberam avaliação positiva em dois dos gêneros propostos. Os dados indicam que há a necessidade de debate sobre as proposições e inserções dessas janelas a partir dos gêneros discursivos e não por uma imposição normativa estanque, bem como a necessidade de mais estudos de recepção junto à comunidade surda em relação à TIALS. Palavras-chave: Tradução Audiovisual; Tradução Audiovisual Acessível; Mídias Acessíveis; Janela de Libras; Estudo de Recepção
\end{abstract}

${ }^{1}$ Pesquisa realizada com Auxílio Regular à Pesquisa da Fundação de Amparo à Pesquisa do Estado de São Paulo (FAPESP - Processo: 2017/21970-9). 


\title{
AUDIOVISUAL SIGN LANGUAGE TRANSLATION AND INTERPRETATION IN BRAZIL: A RECEPTION STUDY ON REGARDING SCREEN INSET/INTERPRETER SPACE PLACEMENT AND SIZING IN DEAF COMMUNITY
}

\begin{abstract}
This article presents the results of a nationwide survey aimed at understanding the preferences of the Deaf regarding screen insets [interpreter spaces] for audiovisual translation and interpretation into Brazilian Sign Language. Data was collected through an online bilingual questionnaire that was circulated on social media and specifically addressed to the Brazilian Deaf community. It consisted of five screeninset [interpreter-space] choices for three audiovisual genres: featurelength comedy film; TV journalism / news; and online education / virtual classroom. Respondents watched videos with placement and size variations of the Brazilian Sign Language screen inset [interpreter space] and rated each option on a scale of 1 (poor) to 5 (excellent). The data shows that preferences change according to genre. The same placement and size variations were scored quite differently for each of the three genres, showing there is a crucial need to address the underlying proposals and placement of screen insets [interpreter space] through a genre-based lens and to avoid imposing size and placement based on fixed standards, as well as the need for more reception studies with the deaf community about audiovisual Sign Language translation.
\end{abstract}

Keywords: audiovisual translation; acessible audiovisual translation; acessible media; Sign Language screen inset; reception study

\section{Introdução}

Em artigo publicado na primeira edição do Journal of Audiovisual Translation (JAT) da European Association for Studies in Screen Translation (ESIST), Frederic Chaume, professor do Departamento de Tradução e Comunicação da Universitat Jaume I realizou uma avaliação detalhada do panorama social e científico das produções atreladas ao profícuo e promissor campo da tradução audiovisual (TAV) descrevendo quatro grandes viradas me-

Cad. Trad., Florianópolis, v. 41, $\mathbf{n}^{0}$ esp. 2, p. 163-201, ago/dez, 2021. 164 
todológicas que impactaram de forma significativa a produção de conhecimento sobre o tema.

A primeira relaciona-se aos estudos descritivos da tradução que trouxeram contribuição significativa para a TAV por permitirem uma observação detalhada dos processos envolvidos nesses contextos. A segunda veio com a ampliação dos estudos sociológicos que inseriram no panorama da TAV a participação do público no processo de criação e circulação da prática tradutória demonstrando uma participação ativa dos consumidores graças à democratização da tecnologia e do acesso à internet. A terceira corresponde aos estudos cognitivos que contribuíram de forma significativa com a compreensão sobre o que acontece com o cérebro de quem produz e de quem recebe a TAV em diferentes aspectos. E, por fim, os estudos de caso com base em abordagens culturais que apresentaram uma perspectiva híbrida na análise de casos envolvendo a produção e recepção da tradução com base em conceitos como alteridade, ideologia, poder etc.

Romero-Fresco, em artigo publicado na mesma edição do $J A T$, salienta que a primeira década do século XXI foi extremamente produtiva para a TAV que tem ultrapassado os limites dos Estudos da Tradução (ET) e vem se destacando como uma ponte de mediação com outras áreas do conhecimento. Para o autor, no entanto, existe uma temática presente em TAV que tem ganhado ainda mais destaque: os estudos sobre as mídias acessíveis que compõem a submodalidade Tradução Audiovisual Acessível (TAVa).

No panorama de Chaume há uma referência específica à TAVa quando o autor evidencia que, a partir dos estudos cognitivos e sociológicos, pesquisas sobre o uso de legendas para surdos e ensurdecidos e audiodescrição para pessoas com deficiência visual têm sido realizadas tanto do ponto de vista da produção quanto da recepção. Greco (211), entretanto, discutindo a relação entre os Estudos da Acessibilidade e a TAV, destaca que houve ampliação do campo "[...] para incluir outras modalidades, como legendagem de áudio e interpretação de língua de sinais [...]"2. A afirmação do autor mos-

${ }^{2} \mathrm{Na}$ fonte: It was at times expanded to include other modalities, such as audio

Cad. Trad., Florianópolis, v. 41, $\mathbf{n}^{0}$ esp. 2, p. 163-201, ago/dez, 2021. 165 
tra um hiato no panorama de Chaume que, apesar de amplo, não incluiu, por exemplo, a interpretação e a tradução intermodal ${ }^{3}$.

Nascimento e Nogueira advogam que a ausência da citação sobre a tradução e a interpretação intermodal no mapeamento de Chaume revela uma tendência comum dos Estudos nacionais e internacionais em TAV e em TAVa que ora as excluem do cenário audiovisual, ora consideram apenas a interpretação em programas ao vivo sem muitas discussões sobre o assunto. Segundo os autores, pesquisadores brasileiros vêm demonstrando que a tradução intermodal, por exemplo, pode se enquadrar na "[...] conceituação de tradução audiovisual por mobilizar línguas e culturas em plataformas multimodais audiovisuais" (Nascimento e Nogueira 119) e por envolver planejamento, estudo prévio, pesquisa terminológica, refacção textual e revisão.

Todavia, os autores, que debatem o tema a partir da realidade brasileira, destacam que o fato de a inserção da tradução intermodal em meios audiovisuais ser uma temática recente há constante confusão entre o que é o texto traduzido ou interpretado e o que é seu locus de apresentação tanto nas pesquisas quanto nos documentos legais. Nesse último caso, a expressão janela de Libras é utilizada para designar o espaço de apresentação do texto produzido em língua de sinais em documentos oficiais e em pesquisas sobre o tema. Porém, para os autores, "[...] janela não é sinônimo de tradução e, portanto, pesquisas podem - e devem - ser realizadas nas duas direções" (Nascimento e Nogueira 126).

A expressão janela de Libras tem sido usada indiscriminadamente na legislação e em alguns estudos como sinônimo de tradução e interpretação sem as devidas especificações. Entretanto,

subtitling and sign language interpreting [...].

${ }^{3}$ As expressões tradução e interpretação intermodal são cunhadas por alguns pesquisadores ( $C f$. Segala; Quadros e Segala; Rodrigues) para se referirem aos processos de translação de textos que são produzidos e recebidos por canais biofisiológicos distintos. Rodrigues (114) utiliza o termo intramodal para processos de translação em que os sistemas linguísticos possuem os mesmos sistemas de produção e de recepção.

Cad. Trad., Florianópolis, v. 41, $\mathbf{n}^{0}$ esp. 2, p. 163-201, ago/dez, 2021.166 
não há, ainda, um consenso sobre a designação adequada a ser utilizada para referenciar a atuação de tradutores e de intérpretes intermodais em contextos audiovisuais. Nascimento e Nogueira, por exemplo, propõem a expressão Tradução Audiovisual da Língua de Sinais (TALS) a fim de englobar o locus de exibição e a prática tradutória per se. Alguns autores, entretanto, utilizam o termo legenda de Libras ( $C f$. Albres, Silva), mas, conforme afirmam Nascimento, Fornari e Segala (648),

as diferenças de modalidade linguística implicadas nesse tipo de tradução, a multimodalidade constitutiva das mídias audiovisuais e a interrelação entre ambas demandam mais estudos e pesquisas que confirmem a similaridade de tal recurso com as tradicionais legendas que exibem textos escritos.

Neste artigo, a fim de ampliar a discussão de Nascimento e Nogueira, acrescenta-se interpretação à proposta e assume-se a expressão tradução e interpretação audiovisual da língua de sinais (TIALS) como grande categoria conceitual que engloba práticas e processos tradutórios e interpretativos intermodais e janelas de Libras, tal como na legislação brasileira, para indicar o espaço de apresentação/exibição do texto em língua de sinais em materiais audiovisuais.

No Brasil, a TIALS apareceu, pela primeira vez, como direito da comunidade surda no início dos anos 2000. Dentre os diversos documentos que abordam o tema, a lei 10.098/00, que foi a primeira a tratar da acessibilidade de pessoas com deficiência sensorial ao audiovisual, abriu um precedente importante para o debate sobre os direitos linguísticos dos surdos nesse contexto com a determinação da criação de um plano técnico com o "[...] objetivo de permitir o uso da linguagem de sinais ou outra subtitulação, para garantir o direito de acesso à informação às pessoas portadoras de deficiência auditiva, na forma e no prazo previstos em regulamento" 
$(\text { Brasil s/p) })^{4}$. O uso das obsoletas expressões "linguagem de sinais" e "pessoa portadora de deficiência" revelam o quanto se avançou depois da publicação desta lei.

A Associação Brasileira de Normas Técnicas (ABNT) criou, em 2005, a norma brasileira (NBR) 15.290/05, acessibilidade em comunicação na televisão, que apresentou as primeiras diretrizes gerais a serem observadas para a promoção da acessibilidade na televisão. Os documentos subsequentes, como a Portaria 310 do Ministério das Comunicações que publicou a Norma Complementar n ${ }^{\circ}$ 1/2006 com o objetivo de tornar a programação televisiva acessível para pessoas com deficiência, intensificou o debate sobre esse direito.

$\mathrm{Na}$ década de 2010, outros importantes documentos deram maior sustentação jurídica aos direitos linguísticos dos surdos em diferentes esferas sociais incluindo, aí, o meio audiovisual. Caso da Lei Brasileira de Inclusão (LBI), 13.146/15, que tornou obrigatória a inserção da tradução e da interpretação intermodal em programações exibidas em rede nacional, em discursos oficiais, propagandas eleitorais obrigatórias e debates políticos ao vivo. $\mathrm{O}$ impacto da LBI foi, sobretudo, na esfera política que fez com que produtores, redes televisivas e políticos apresentassem seus conteúdos com tradução e interpretação em Libras em anos eleitorais.

A esfera cinematrográfica também foi impactada devido às instruções normativas (I.N.) publicadas pela Agência Nacional do Cinema (ANCINE). Em 2014, foi publicada a I.N. No 116 que determinou que todos os projetos de produção audiovisual financiados com recursos públicos federais deveriam contemplar nos

\footnotetext{
${ }^{4}$ Grifo meu. Segundo Nascimento (390) "o uso das expressões 'linguagem de sinais' e 'pessoa portadora de deficiência' são citações literais do documento e revelam o quanto se avançou depois da publicação dessa lei”. A primeira expressão era utilizada com base na ideia de que as línguas de sinais são universais e que, por isso, os "gestos" produzidos pelos seus falantes seriam facilmente compreendidos por qualquer pessoa. E a expressão “pessoa portadora de deficiência”, por sua vez, apesar de ser utilizado na Constituição de 1988 ( $C f$. Schmidt), não é mais utilizada porque dá a entender que a deficiência é portada ou carregada pelo indivíduo como se fosse algo externo a ele e não intrínseco.
}

Cad. Trad., Florianópolis, v. 41, $\mathrm{n}^{0}$ esp. 2, p. 163-201, ago/dez, 2021. 168 
seus orçamentos serviços de legendagem, legendagem descritiva, audiodescrição e Libras e, em 2016, a I.N. Nº 128 com normas e critérios básicos de acessibilidade visual e auditiva a serem observados nos segmentos de distribuição e exibição cinematográfica (Cf. Nascimento).

A discussão sobre a tradução e interpretação intermodal audiovisual no contexto brasileiro confirma o debate de Chaume, RomeroFresco e Greco sobre a ampliação da TAV em mídias acessíveis. Entretanto, a imposição da produção dessas mídias para surdos pela legislação na realidade brasileira, a escassez de pesquisas ligadas ao tema e a pouca entrada da discussão sobre as especificidades da acessibilidade na formação de profissionais do audiovisual dificultam a promoção dos direitos da população surda nesse meio. Somado a isso, a falta de avaliação e fiscalização quanto aos serviços oferecidos tem levado a produção da tradução e da interpretação, bem como de janelas, com diferentes níveis de qualidade.

Diante da nova realidade de direitos linguísticos para surdos impulsionada pela legislação nas duas últimas décadas no contexto brasileiro, da pluralidade tipológica das janelas nas produções audiovisuais e da tímida produção acadêmica sobre o assunto, questiona-se quais seriam as propostas de janelas de Libras mais confortáveis para a visualização da tradução e interpretação de língua de sinais pelos surdos. Nesse sentido, neste artigo, são apresentados resultados de uma pesquisa de recepção de amplitude nacional realizada no Laboratório de Tradução Audiovisual da Língua de Sinais (LATRAVILIS) da Universidade Federal de São Carlos (UFSCar) que objetivou avaliar a preferência dos surdos pelas janelas de Libras inseridas em diferentes produções audiovisuais.

\section{Aspectos teórico-metodológicos}

Esta pesquisa foi aprovada pelo Comitê de Ética em Pesquisa da UFSCar (CAAE: 89468318.5.0000.5504). Por trabalhar com dados objetivos de uma perspectiva analítica, exploratória e crítica

Cad. Trad., Florianópolis, v. 41, $\mathrm{n}^{0}$ esp. 2, p. 163-201, ago/dez, 2021. 169 
este estudo se caracteriza como quanti-qualitativo, pois busca "[...] trazer à luz dados, indicadores e tendências observáveis [...]" sobre a preferência dos surdos em relação às janelas de Libras e, com isso, problematizar "[...] fatos e processos particulares e específicos [...]" (Minayo \& Sanches, 247) em função dessa percepção. Para a coleta de dados optou-se pelo questionário como dispositivo metodológico, visto que ele se constitui como uma "[...] técnica de investigação composta por um conjunto de questões que são submetidas a pessoas com o propósito de obter informações sobre conhecimentos, crenças, sentimentos [...] etc." (Gil, 121).

$\mathrm{Na}$ descrição da virada metodológica promovida pelos estudos sociológicos, Chaume (47) chama atenção para a nova cultura digital que está sendo promovida com a digitalização. Segundo ele, "um novo uso, mais interativo e dinâmico da web, também convida o público anteriormente passivo a participar da criação e tradução de conteúdo audiovisual, do desenvolvimento de novas idéias e da complexa interação da criatividade coletiva"5. Nessa direção, o autor destaca alguns instrumentos metodológicos que permitem mapear e descrever a relação entre público-alvo e obra traduzida, dentre os quais encontram-se os questionários que permitem ao pesquisador "[...] a capacidade de criar estratégias e acompanhar as tendências do público. A análise de dados coletados por essas ferramentas pode ser usada para gerar previsões e até substituir hábitos

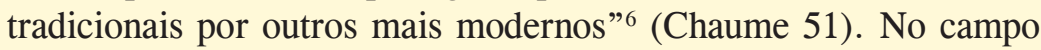
da TAV, os questionários, conforme defende Tuominen (69), se apresentam como dispositivos que permitem a construção de modelos de tradução centrados na experiência e usabilidade do usuário.

${ }^{5} \mathrm{Na}$ fonte: $A$ new, more interactive and dynamic use of the web also invites formerly passive audiences to participate in the creation and translation of audiovisual content, in the development of new ideas and in the complex interplay of collective creativity.

${ }^{6} \mathrm{Na}$ fonte: The more data the researcher gathers, the clearer the picture becomes. All this information gives stakeholders the ability to create new strategies and follow audience trends. Analysing data gathered via these tools can be used to generate predictions and even replace traditional habits with more modern ones.

Cad. Trad., Florianópolis, v. 41, $\mathbf{n}^{0}$ esp. 2, p. 163-201, ago/dez, 2021.170 
A utilização de questionários em pesquisas quantitativas pode acontecer via (i) tradução e adaptação de questionários já existentes ou (ii) elaboração e validação de um novo questionário. Deliza, Rosenthal e Costa (44) salientam que a falta de um instrumento de pesquisa na língua desejada mobiliza pesquisadores a acenarem para o desenvolvimento de novos no próprio idioma, demandando, com isso, um processo de criação, validação e revalidação. Movimentos diferentes de um questionário traduzido que envolve "um processo de adaptação cultural e posterior avaliação da validade da nova versão".

A decisão pela criação de um instrumento próprio justifica-se por não ter sido encontrado na literatura nacional qualquer estudo de grande amplitude que indicasse a avaliação de janelas exclusivamente por surdos. Alguns estudos brasileiros se direcionaram para a avaliação de janelas como, por exemplo, Novaes que avaliou as variáveis do posicionamento da janela na tela e tamanho do vídeo-fonte a partir da aplicação de um questionário com surdos $e$ ouvintes e, também, a pesquisa de Cardoso, Nogueira e Zardo que analisaram, a partir de um teste de recepção com surdos gaúchos em um grupo focal, opiniões sobre a tradução de produtos audiovisuais em três diferentes formatos e posicionamento do intérprete. Nenhuma dessas propostas, entretanto, investigou a relação da janela com gêneros diferentes ou exclusivamente com surdos em dimensão nacional.

O questionário proposto, então, focou na percepção dos surdos, na posição de interlocutores, sobre formas de exibição e veiculação de sua língua em produções audiovisuais e envolveu diferentes materialidades semióticas - verbais, não-verbais e verbo-visuais - demandando, com isso, reflexões de cunho teórico-metodológico para fundamentar todo o processo de construção do instrumento. Para isso, adotou-se a perspectiva bakhtiniana ${ }^{7}$ de análise de

${ }^{7}$ A perspectiva bakhtiniana corresponde à maneira como Mikhail M. Bakhtin, filósofo russo, em diálogo com outros intelectuais no início do século $\mathrm{XX}$, em especial Valentin Volóchinov e Pavel Medviédev, conceberam a linguagem no âmbito da cultura, da literatura, da estética, das artes e da comunicação (Brait).

Cad. Trad., Florianópolis, v. 41, $\mathbf{n}^{0}$ esp. 2, p. 163-201, ago/dez, 2021. 171 
materiais semiótico-ideológicos ( $C f$. Bakhtin; Volochínov) e suas contribuições para o estudo da verbo-visualidade ( $C f$. Brait) e da tradução e interpretação intermodal (Cf. Segala; Nascimento; Rodrigues; Rodrigues e Santos; Nascimento e Nogueira) como base conceitual em toda a pesquisa.

O questionário foi elaborado na plataforma Google forms e foi produzido em língua portuguesa e em Libras em três diferentes fases:

Quadro 1 - fases da pesquisa

FASE 1 discussão do formato e da redação das perguntas com equipe de tradução e com a equipe que atuou na edição do questionário

FASE 2 tradução para a Libras

FASE 3 validação por avaliadores surdos

Fonte: elaborado pelo autor

O instrumento foi abordado como um "gênero secundário" (Bakhtin, 15) que mobilizou a dimensão verbo-visual da linguagem a partir da tradução intermodal considerando a impossibilidade de separação da dimensão verbal e visual no processo tradutório, visto que os elementos extralinguísticos poderiam ser absorvidos durante a tradução para a língua de sinais.

A versão final do questionário (anexo 1) ficou composto por: (i) apresentação e Termo de Consentimento Livre e Esclarecido (TCLE), no qual o respondente pôde compreender os detalhes da pesquisa e aceitar ou não participar do estudo e realizar a autodeclaração de que era surdo; (ii) dados pessoais; (iii) perfil sociolinguístico, em que o participante pode dizer qual a língua que utiliza para se comunicar, sobre seu processo e nível educacional, sua relação com obras audiovisuais e experiência com tradução e interpretação em fase escolar; e por fim (iv) questões sobre as

Cad. Trad., Florianópolis, v. 41, $\mathrm{n}^{0}$ esp. 2, p. 163-201, ago/dez, 2021. 172 
janelas, que apresentaram as diferentes propostas de janelas que deveriam ser avaliadas.

No item (iv) do questionário, os respondentes avaliaram cinco tipos de janelas para três gêneros diferentes: cinematográfico-comédia, jornalístico-televisivo e videoaula. Os gêneros mobilizam práticas de tradução, caso do primeiro e do último, e de interpretação, caso do segundo, considerando que telejornais são geralmente transmitidos ao vivo. As janelas foram elaboradas a partir de dois critérios: (i) proposições oficiais como da NBR 15290/05 da ABNT e do Guia de Produções Audiovisuais Acessíveis do Ministério da Cultura (doravante Guia); e (ii) proposição mercadológica com circulação em plataformas virtuais. Nesse sentido, dos cinco tipos de janelas, foram adotadas quatro variações para os três gêneros sendo que as três primeiras seguiram o tamanho proposto pela NBR 15290/05: (a) janela com fundo branco; (b) janela translúcida; (c) janela transparente; e (d) janela deslocada em Picture In Picutre (proposta do Guia). E a última janela considerou a proposta do mercado para cada gênero. Para o cinematográfico adotou-se a proposta da produtora Filmes que voam ${ }^{8}$, no jornalístico televisivo, adotou-se a proposta do Tribunal Superior

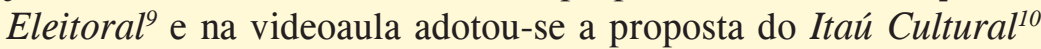
(figuras 1, 2 e 3). Na época da elaboração do questionário, não havia muitas propostas para o gênero jornalístico circulando. Por isso, adotou-se um modelo governamental como sendo um possível tipo para uso no gênero televisivo.

\footnotetext{
${ }^{8}$ Modelo disponível em: https://www.youtube.com/watch? $\mathrm{v}=\operatorname{Pg} 7 \mathrm{ks} 30 A v M U$.

${ }^{9}$ Modelo disponível em: https://www.youtube.com/watch? $\mathrm{v}=\mathrm{g} 3 \mathrm{dnDilJAD} 0$.

${ }^{10}$ Modelo disponível em: https://youtu.be/r4pgT3Gk7e4.
}

Cad. Trad., Florianópolis, v. 41, $\mathrm{n}^{0}$ esp. 2, p. 163-201, ago/dez, 2021. 173 
Figura 1: Janelas de Libras propostas para avaliação a partir do gênero cinematográfico comédia

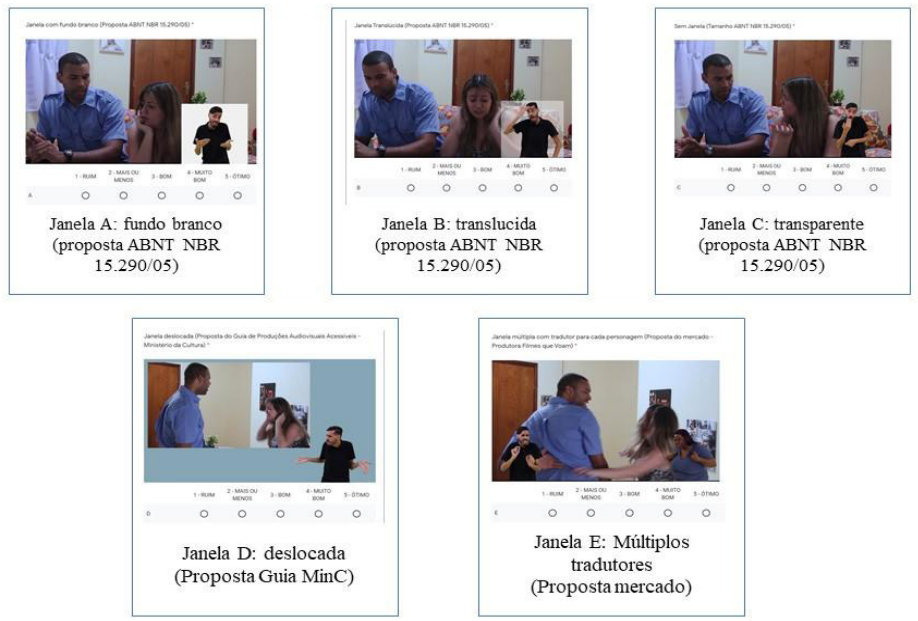

Fonte: elaborado pelo autor

Cad. Trad., Florianópolis, v. 41, $\mathbf{n}^{0}$ esp. 2, p. 163-201, ago/dez, 2021. 174 
Figura 2: Janelas de Libras propostas para avaliação a partir do gênero jornalístico televisivo

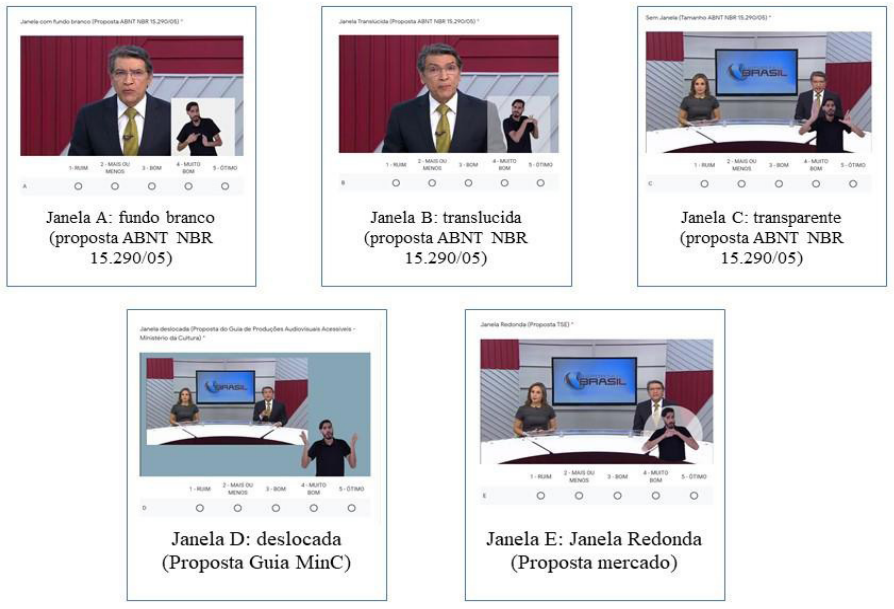

Fonte: elaborado pelo autor

Cad. Trad., Florianópolis, v. 41, $\mathrm{n}^{0}$ esp. 2, p. 163-201, ago/dez, 2021. 175 
Figura 3: Janelas de Libras propostas para avaliação a partir do gênero videoaula

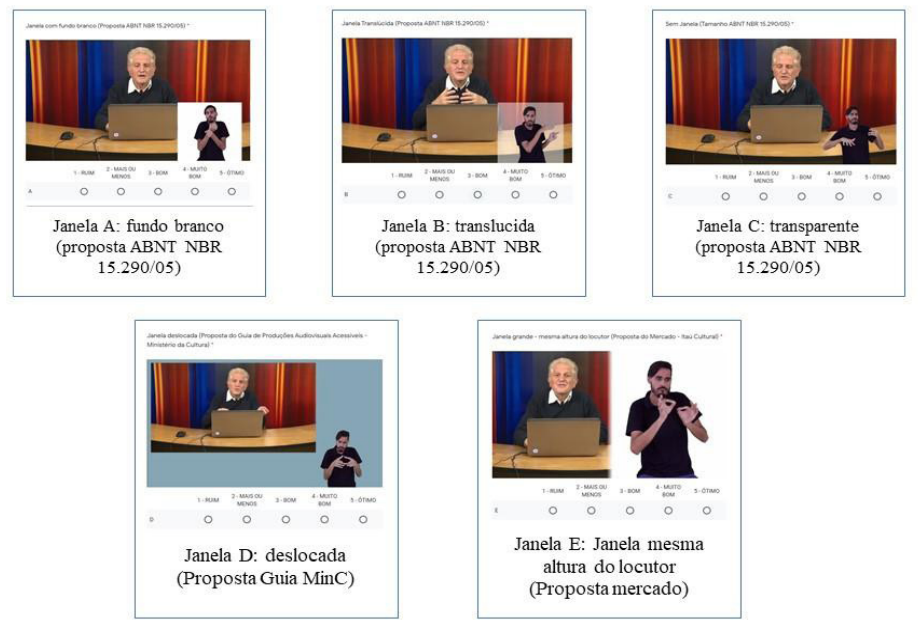

Fonte: elaborado pelo autor

Os respondentes assistiram um vídeo de aproximadamente 30" com cada proposta e depois as avaliaram dando notas de 1 a 5 para cada uma das janelas sendo que 1 correspondeu a "ruim" e 5 a "excelente", conforme apresenta a figura 4.

Figura 4: Escala de avaliação para cada janela de Libras.

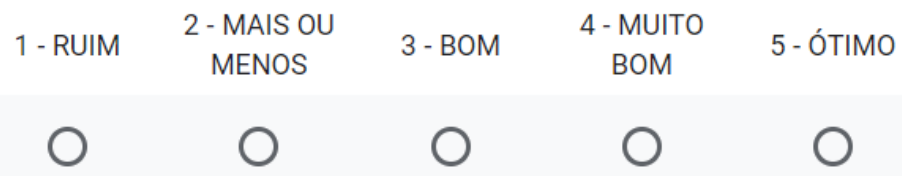

Fonte: elaborado pelo autor

Cad. Trad., Florianópolis, v. 41, $\mathrm{n}^{0}$ esp. 2, p. 163-201, ago/dez, 2021. 176 
A descrição detalhada do processo de tradução, revisão e validação do questionário pode ser encontrado em Nascimento, Fornari e Segala e uma simulação de resposta ao questionário pode ser visualizada no link: https://www.youtube.com/watch?v=eV35JZnWiaA.

Nesse artigo, apresenta-se dados do item (iv) questões sobre as janelas.

\section{Resultados e discussão}

O questionário foi respondido por 183 pessoas de 25 das 27 unidades federativas do Brasil. No início do questionário, o respondente poderia escolher se aceitava ou não participar da pesquisa. Dos que responderam, 15 clicaram em "não aceito participar" e, por isso, foram consideradas apenas as respostas dos que chegaram ao fim do questionário o submetendo ao seu término. A análise considerou, então, 168 de 183 respostas. A maior parte dos respondentes se concentrou no estado de São Paulo, seguido do Ceará, Rio de Janeiro, Minas Gerais, Goiás e Rio Grande do Sul.

Figura 5: relação de participantes por estado.

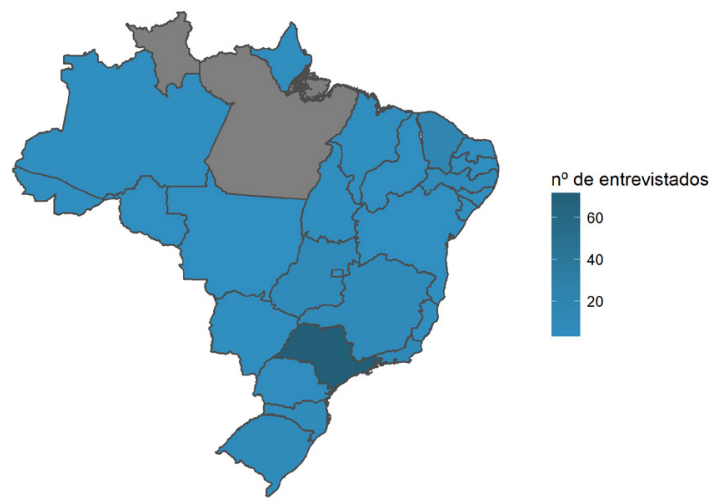

Fonte: elaborado pelo autor

Cad. Trad., Florianópolis, v. 41, $\mathrm{n}^{0}$ esp. 2, p. 163-201, ago/dez, 2021. 177 
No item (iv) do questionário foi apresentado ao respondente as cinco propostas de janelas para os três gêneros selecionados sendo que o primeiro a ser avaliado foi o cinematográfico. A inclusão desse gênero audiovisual baseou-se na exigência da ANCINE, via I.N., de inserção dos três recursos de acessibilidade (legenda, Libras e audiodescrição) em peças produzidas com recursos públicos. Partiu-se do pressuposto de que os produtores seguem as normas orientacionais vigentes - ABNT e Guia - na elaboração das janelas. Todavia, considerou-se que a última variação a ser avaliada - a da janela múltipla - que é uma proposição do mercado - deveria ser testada também, visto que não houve avaliação ampla desse novo formato junto aos surdos. Abaixo apresenta-se as avaliações das janelas de Libras a partir dos três gêneros propostos.

\subsection{Avaliação do gênero cinematográfico-comédia}

No gênero cinematográfico-comédia, a variação (a) janela com fundo branco recebeu a pior avaliação (67\% dos votos em ruim) conforme tabela 1 . A proposta (b) translúcida, concentra a maior parte das avaliações na categoria "mais ou menos" (42\%). As variações (c) janela transparente e a (c) janela múltipla receberam melhor avaliação que as outras. O que se observa, portanto, é a rejeição majoritária da variação (a). A proposta (d), janela deslocada do Guia, entretanto, teve avaliação simétrica, mas, ainda assim, apresentou rejeição do público. E a proposta do mercado - janela (e) - foi a que recebeu a melhor avaliação entre todas as propostas (37\% em ótimo).

Cad. Trad., Florianópolis, v. 41, $\mathrm{n}^{0}$ esp. 2, p. 163-201, ago/dez, 2021. 178 
Tabela 1: Avaliação das janelas do gênero cinematográfico comédia

CLASSIFICAÇÃO

TIPOS DE JANELAS

\begin{tabular}{|c|c|c|c|c|c|c|c|c|c|c|}
\hline & \multicolumn{2}{|c|}{ a) ABNT 1} & \multicolumn{2}{|c|}{ b) ABNT 2} & \multicolumn{2}{|c|}{ c) ABNT 3} & \multicolumn{2}{|c|}{ d) Guia } & \multicolumn{2}{|c|}{ e) Mercado } \\
\hline & \multicolumn{2}{|c|}{ Fundo branco } & \multicolumn{2}{|c|}{ Translúcida } & \multicolumn{2}{|c|}{ Transparente } & \multicolumn{2}{|c|}{ Deslocada } & \multicolumn{2}{|c|}{$\begin{array}{l}\text { Janela } \\
\text { múltipla }\end{array}$} \\
\hline & $\begin{array}{l}\text { Freq. } \\
\text { Abs. }\end{array}$ & $\begin{array}{l}\text { Freq. } \\
\text { Rel. }\end{array}$ & $\begin{array}{l}\text { Freq. } \\
\text { Abs. }\end{array}$ & $\begin{array}{l}\text { Freq. } \\
\text { Rel. }\end{array}$ & $\begin{array}{l}\text { Freq. } \\
\text { Abs. }\end{array}$ & $\begin{array}{l}\text { Freq. } \\
\text { Rel. }\end{array}$ & $\begin{array}{l}\text { Freq. } \\
\text { Abs. }\end{array}$ & $\begin{array}{l}\text { Freq. } \\
\text { Rel. }\end{array}$ & $\begin{array}{l}\text { Freq. } \\
\text { Abs. }\end{array}$ & $\begin{array}{l}\text { Freq. } \\
\text { Rel. }\end{array}$ \\
\hline 1 RUIM & 112 & $67 \%$ & 45 & $27 \%$ & 23 & $14 \%$ & 38 & $23 \%$ & 25 & $15 \%$ \\
\hline $\begin{array}{l}2 \text { MAIS OU } \\
\text { MENOS }\end{array}$ & 24 & $14 \%$ & 70 & $42 \%$ & 29 & $17 \%$ & 36 & $21 \%$ & 21 & $13 \%$ \\
\hline $3 \mathrm{BOM}$ & 12 & $7 \%$ & 30 & $18 \%$ & 49 & $29 \%$ & 33 & $20 \%$ & 22 & $13 \%$ \\
\hline 4 MUITO BOM & 10 & $6 \%$ & 16 & $10 \%$ & 24 & $14 \%$ & 27 & $16 \%$ & 38 & $23 \%$ \\
\hline 5 ÓTIMO & 10 & $6 \%$ & 7 & $4 \%$ & 43 & $26 \%$ & 34 & $20 \%$ & 62 & $37 \%$ \\
\hline
\end{tabular}

Fonte: elaborado pelo autor

A última janela apresenta um tradutor para cada personagem no tamanho proposto pela NBR 15.290/05 da ABNT que aparecem de acordo com os personagens e somem quando eles também somem da tela. Quando há a presença de mais de um personagem e sobreposição de falas, por exemplo, os tradutores aparecem todos juntos possibilitando ao expectador surdo perceber esses fenômenos. A proposta tem sido adotada por algumas produtoras e é algo completamente novo frente ao que é oferecido aos surdos, mas, ainda assim, recebeu avaliação positiva sendo a proposta com o maior número de avaliações em "ótimo” (37\%). Essa repercussão positiva pode ser associada a alguns fatores.

O primeiro fator seria a possibilidade de acompanhar visualmente os tradutores e os personagens nas telas simultaneamente. Nogueira e Alves (267) descrevem esse modelo de janela e debatem os processos de tradução nele envolvidos. Segundo os autores, o modelo com um tradutor para cada personagem "visa definir claramente para o público que está acompanhando o filme

Cad. Trad., Florianópolis, v. 41, n $^{0}$ esp. 2, p. 163-201, ago/dez, 2021. 179 
com a tradução qual é o personagem que naquele momento está se expressando".

Figura 6: tradutor por personagem em uma produção de curtametragem

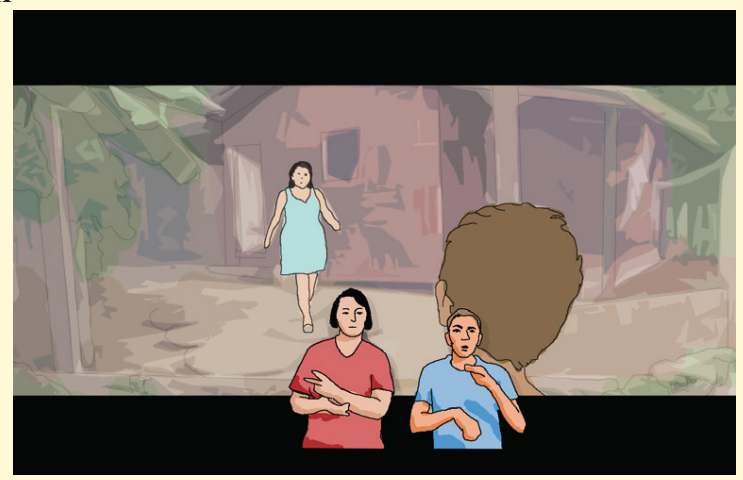

Fonte: Nogueira e Alves (267)

Até o momento existem poucos estudos que investigam a relação entre percepção visual da tradução e interpretação intermodal e seus efeitos no cérebro. Um dos estudos que se direcionam para esse fim foi o desenvolvido por Wehrmeyer que investigou, por meio de rastreamento ocular, os hábitos de adultos surdos e ouvintes durante a visualização de notícias com interpretação para a língua de sinais na África do Sul. O estudo revelou que espectadores surdos se concentram principalmente no intérprete e, secundariamente, nas imagens e os espectadores ouvintes priorizam o conteúdo pictórico, mas também gastam proporções significativas de tempo examinando legendas, leitura labial ou até mesmo assistindo o intérprete. $\mathrm{O}$ estudo, porém, não discutiu padrões de tamanho e posicionamento da janela de interpretação.

Já no estudo de Bosch-Baliarda, Soler-Vilageliu e Orero foi realizada uma correlação entre tamanho e posicionamento de janela com a percepção, por meio de rastreamento ocular, de 32 surdos usuários da língua de sinais espanhola. Os pesquisa-

Cad. Trad., Florianópolis, v. 41, $\mathrm{n}^{0}$ esp. 2, p. 163-201, ago/dez, 2021. 180 
dores apresentaram aos participantes quatro clipes semelhantes com diferentes composições de janelas e registraram o padrão de exploração de tela com o Eye Tracker avaliando a evocação do conteúdo por meio de dois questionários. Os resultados mostraram que os usuários de língua de sinais direcionam seus olhares principalmente para a tela do intérprete de língua de sinais e tendem a olhar com mais frequência e por mais tempo para o lado do intérprete mais perto da tela principal.

No caso da pesquisa aqui descrita, a primeira hipótese para a preferência da janela com múltiplos intérpretes - que precisaria ser investigada com pesquisa empírico-experimental - é que o telespectador surdo, talvez, não perca as informações visuais da peça audiovisual justamente por não direcionar sua atenção exclusivamente a um dos cantos da tela, por exemplo, como acontece com as janelas únicas, mas pode ir acompanhando a totalidade da obra a partir da mudança do posicionamento dos tradutores.

O segundo fator seria a marcação dos personagens por diferentes sujeitos empíricos e não apenas na marcação discursiva em língua de sinais por um tradutor apenas. $\mathrm{O}$ efeito da incorporação de personagens, chamado pela linguística cognitiva de espaço sub-rogado ( $C f$. Moreira), é algo muito presente no discurso das línguas de sinais e adotado, portanto, na tradução e interpretação. Entretanto, como os gêneros audiovisuais cinematográficos acabam, em alguns casos, apresentando inúmeros personagens, a marcação tradutória de cada um deles é algo complexo a ser feito do ponto de vista da execução da tradução e, em alguns casos, pode haver omissão de alguma fala ou marcação dos personagens a depender da quantidade. E o terceiro fator seria que, no limite, os tradutores podem adotar recursos extraverbais na marcação das personagens diferenciando, claramente, quem é quem no vídeo, conforme descrevem Nogueira e Alves (280) que defendem que o uso de "[...] objeto cênico na tradução coloca o ator-tradutor mais próximo do ator-personagem evidenciando a relação com o discurso".

Cad. Trad., Florianópolis, v. 41, $\mathrm{n}^{0}$ esp. 2, p. 163-201, ago/dez, 2021. 181 


\subsection{Avaliação do gênero jornalístico-televisivo}

Se a proposta do mercado no gênero cinematográfico foi a que recebeu melhor avaliação, no gênero jornalístico-televisivo, foi a proposta do Guia que foi mais bem avaliada. Na tabela 2, observa-se que $27 \%$ das avaliações em ótimo indicam positividade e aceitação da proposta para esse gênero, algo diferente do gênero anterior. A variação (c) desta vez recebeu avaliação mais uniforme e a janela (e) proposta especificamente para esse tipo de produção audiovisual recebeu a maioria dos votos em "mais ou menos" tendo pouca aceitação. A janela translúcida continuou com sua maioria concentrada nas más avaliações e a variação (a) se destaca novamente como a mais mal avaliada pelos respondentes.

Tabela 2: Avaliação das janelas do gênero jornalístico televisivo.

CLASSIFICAÇÃO

\begin{tabular}{|c|c|c|c|c|c|c|c|c|c|c|}
\hline & \multicolumn{2}{|c|}{ a) ABNT 1} & \multicolumn{2}{|c|}{ b) ABNT 2} & \multicolumn{2}{|c|}{ c) ABNT 3} & \multicolumn{2}{|c|}{ d) Guia } & \multicolumn{2}{|c|}{ e) Mercado } \\
\hline & \multicolumn{2}{|c|}{ Fundo branco } & \multicolumn{2}{|c|}{ Translúcida } & \multicolumn{2}{|c|}{ Transparente } & \multicolumn{2}{|c|}{ Deslocada } & \multicolumn{2}{|c|}{$\begin{array}{l}\text { Janela } \\
\text { redonda }\end{array}$} \\
\hline & $\begin{array}{l}\text { Freq. } \\
\text { Abs. }\end{array}$ & $\begin{array}{l}\text { Freq. } \\
\text { Rel. }\end{array}$ & $\begin{array}{l}\text { Freq. } \\
\text { Abs. }\end{array}$ & $\begin{array}{l}\text { Freq. } \\
\text { Rel. }\end{array}$ & $\begin{array}{l}\text { Freq. } \\
\text { Abs. }\end{array}$ & $\begin{array}{l}\text { Freq. } \\
\text { Rel. }\end{array}$ & $\begin{array}{l}\text { Freq. } \\
\text { Abs. }\end{array}$ & $\begin{array}{l}\text { Freq. } \\
\text { Rel. }\end{array}$ & $\begin{array}{l}\text { Freq. } \\
\text { Abs. }\end{array}$ & $\begin{array}{l}\text { Freq. } \\
\text { Rel. }\end{array}$ \\
\hline 1 RUIM & 105 & $63 \%$ & 42 & $25 \%$ & 36 & $21 \%$ & 31 & $18 \%$ & 40 & $24 \%$ \\
\hline 2 MAIS OU MENOS & 25 & $15 \%$ & 57 & $34 \%$ & 35 & $21 \%$ & 32 & $19 \%$ & 38 & $23 \%$ \\
\hline $3 \mathrm{BOM}$ & 19 & $11 \%$ & 36 & $21 \%$ & 37 & $22 \%$ & 33 & $20 \%$ & 40 & $24 \%$ \\
\hline 4 MUITO BOM & 9 & $5 \%$ & 15 & $9 \%$ & 22 & $13 \%$ & 26 & $15 \%$ & 30 & $18 \%$ \\
\hline 5 ÓtIM0 & 10 & $6 \%$ & 18 & $11 \%$ & 38 & $23 \%$ & 46 & $27 \%$ & 20 & $12 \%$ \\
\hline
\end{tabular}

Fonte: elaborado pelo autor

Nesse caso, a avaliação positiva da proposta do Guia chama atenção, uma vez que o próprio documento orienta que a proposição da janela no formato Picture in Picture é para o cinema para "[...] garantir a visibilidade da tradução em língua de sinais e não

Cad. Trad., Florianópolis, v. 41, $\mathbf{n}^{0}$ esp. 2, p. 163-201, ago/dez, 2021. 182 
comprometer a visualização da produção audiovisual [...]" (Naves et al. 32). Para a TV, o Guia recomenda respeitar as normas da NBR 15.290/05 da ABNT. Entretanto, as janelas avaliadas com base nas normas da ABNT não receberam avaliação tão positiva quanto a do próprio Guia.

Apesar da Lei 13.146/15 garantir a inserção da tradução e da interpretação da Libras em programações televisivas de diferentes esferas e contextos, com destaque maior na política, não se vê a TV aberta garantindo esse direito, de forma ampla, aos surdos. Segundo Nascimento \& Nascimento a TV Cultura é um dos únicos canais abertos que oferecem serviço de interpretação em telejornais e tradução de entretenimento voltado ao público infantil. Angelim \& Nascimento destacam que em anos eleitorais, por imposição legal, percebe-se que a janela de Libras está lá na maioria das campanhas e debates, mas são apresentas pelas redes televisivas com certo incômodo, pois são geralmente pequenas e os tradutores e os intérpretes são colocados em tamanho menor ainda, de forma inferiorizada, nos cantos das telas com proporcionalidade e texturas bem diferentes das propostas nos documentos orientacionais.

Das redes concessionárias públicas no Brasil atualmente, pouquíssimas oferecem ao telespectador surdo a possibilidade de assistir as programações em sua língua. A ausência da tradução e da interpretação intermodal desconstrói a ideia de que a televisão é um meio de comunicação democrático, pois "os surdos, enquanto telespectadores impossibilitados de apreensão das informações por meio da audição ficam, em parte, de fora no que tange à transmissão da cultura audiovisual [...]" (Nascimento, 41). Nesse sentido, avaliar janelas propostas para esse gênero significa antecipar a aplicação da lei em relação aos direitos dos surdos de acesso à comunicação televisiva.

\subsection{Avaliação do gênero videoaula}

$\mathrm{Na}$ avaliação do gênero videoaula a proposta de janela do mercado seguiu o formato do Itaú Cultural que apresenta o tradutor

Cad. Trad., Florianópolis, v. 41, $\mathbf{n}^{0}$ esp. 2, p. 163-201, ago/dez, 2021.183 
em tamanho equivalente ao da tela da obra audiovisual sem sobreposição. Na tabela 3 observamos que essa proposta recebeu $53 \%$ de avaliações em ótimo sendo, portanto, a proposta mercadológica com melhor avaliação nos três gêneros. A janela (a), mais uma vez, é a que recebe a pior avaliação em relação às outras.

Tabela 3: Avaliação das janelas do gênero videoaula.

\section{CLASSIFICAÇÃO}

\begin{tabular}{|c|c|c|c|c|c|c|c|c|c|c|}
\hline & \multicolumn{2}{|c|}{ a) ABNT 1} & \multicolumn{2}{|c|}{ b) ABNT 2} & \multicolumn{2}{|c|}{ c) ABNT 3} & \multicolumn{2}{|c|}{ d) Guia } & \multicolumn{2}{|c|}{ e) Mercado } \\
\hline & \multicolumn{2}{|c|}{ Fundo branco } & \multicolumn{2}{|c|}{ Translúcida } & \multicolumn{2}{|c|}{ Transparente } & \multicolumn{2}{|c|}{ Deslocada } & \multicolumn{2}{|c|}{$\begin{array}{l}\text { Janela } \\
\text { grande }\end{array}$} \\
\hline & $\begin{array}{l}\text { Freq. } \\
\text { Abs. }\end{array}$ & $\begin{array}{l}\text { Freq. } \\
\text { Rel. }\end{array}$ & $\begin{array}{l}\text { Freq. } \\
\text { Abs. }\end{array}$ & $\begin{array}{l}\text { Freq. } \\
\text { Rel. }\end{array}$ & $\begin{array}{l}\text { Freq. } \\
\text { Abs. }\end{array}$ & $\begin{array}{l}\text { Freq. } \\
\text { Rel. }\end{array}$ & $\begin{array}{l}\text { Freq. } \\
\text { Abs. }\end{array}$ & $\begin{array}{l}\text { Freq. } \\
\text { Rel. }\end{array}$ & $\begin{array}{l}\text { Freq. } \\
\text { Abs. }\end{array}$ & $\begin{array}{l}\text { Freq. } \\
\text { Rel. }\end{array}$ \\
\hline 1 RUIM & 96 & $57 \%$ & 44 & $26 \%$ & 29 & $17 \%$ & 39 & $23 \%$ & 19 & $11 \%$ \\
\hline 2 MAIS OU MENOS & 29 & $17 \%$ & 57 & $34 \%$ & 27 & $16 \%$ & 33 & $20 \%$ & 10 & $6 \%$ \\
\hline $3 \mathrm{BOM}$ & 20 & $12 \%$ & 41 & $24 \%$ & 49 & $29 \%$ & 38 & $23 \%$ & 25 & $15 \%$ \\
\hline 4 MUITO ВOM & 14 & $8 \%$ & 18 & $11 \%$ & 24 & $14 \%$ & 38 & $23 \%$ & 25 & $15 \%$ \\
\hline 5 ÓTIM0 & 9 & $5 \%$ & 8 & $5 \%$ & 39 & $23 \%$ & 20 & $12 \%$ & 89 & $53 \%$ \\
\hline
\end{tabular}

Fonte: elaborado pelo autor

A avaliação extremamente positiva da janela proposta pelo mercado pode ser associada à visibilidade que a língua de sinais ganha nesse tipo de janela. $\mathrm{O}$ tradutor deixa de estar minorizado no canto da tela e ganha proporções significativas em relação ao orador colocando a língua de sinais no mesmo patamar da língua vocal. Além disso, como o gênero corresponde a uma aula expositiva, ter o tradutor ou o intérprete em tamanho grande permite ao aluno o acesso aos conteúdos de forma parecida com o que ele recebe em sala de aula quando acompanhado desses profissionais. Se os gêneros do discurso, conforme defende Bakhtin, não podem ser definidos por suas relações lógicas, abstratas e sistêmicas, mas pelas relações dialógicas, ou seja, pela indissociabilidade entre enuncia-

Cad. Trad., Florianópolis, v. 41, $\mathbf{n}^{0}$ esp. 2, p. 163-201, ago/dez, 2021. 184 
dor, enunciado e contexto de produção do discurso, a tradução e a interpretação intermodal na videoaula ganham outra dimensão em relação aos outros gêneros.

O fato de a visibilidade da língua de sinais suscitar no público-alvo uma identificação com o objeto da tradução ou da interpretação e, ainda, podemos inferir, uma memória de um outro espaço de circulação do discurso, a sala de aula com a presença de intérpretes, indica que tanto a tradução quanto a interpretação intermodal em meios audiovisuais não podem ser pensadas de forma homogênea, mas pelas especificidades de cada contexto de produção.

\section{Considerações finais}

A pesquisa aqui descrita objetivou avaliar a preferência dos surdos pelas janelas de Libras em diferentes gêneros do discurso. Observa-se, pelos dados analisados, que as mesmas janelas apresentadas nos três gêneros receberam avaliações diferentes. Nas variações apresentadas, a proposta da ABNT com fundo branco foi a que recebeu a pior avaliação em todos os gêneros. Percebe-se, também, que a aceitação das propostas oficiais variou contrariando, inclusive, a própria recomendação dos documentos, como foi o caso da proposta do Guia que foi elaborado para produções audiovisuais cinematográficas. Nesse caso, houve rejeição da janela elaborada para o gênero produzido para a grande tela e grande aceitação da proposta no gênero produzido para a TV aberta, o que indica a necessidade de avaliação pelo público-alvo de proposições que se apresentem como oficiais.

As propostas retiradas do mercado audiovisual também receberam avaliações diferentes. Enquanto no gênero cinematográfico e na videoaula a proposição mercadológica recebeu avaliação positiva, no gênero jornalístico foi o da norma orientacional que foi bem aceita o que indica, também, que nem sempre as novas formas e tentativas de circulação da língua de sinais propostas pelo mercado serão bem aceitas. Por outro lado, o que se observa nas propostas

Cad. Trad., Florianópolis, v. 41, $\mathrm{n}^{0}$ esp. 2, p. 163-201, ago/dez, 2021. 185 
do mercado é que há a preocupação com as formas de apresentação da língua de sinais e de compreensão por parte do surdo evidenciado na inserção de mais de um tradutor - no caso do primeiro gênero - e na janela aumentada - no caso do último. Nesse prisma, os documentos orientacionais, embora se preocupem com apresentação da tradução e interpretação, inclinam-se mais para a boa visualização da obra.

Este foi um estudo inicial e que aponta para a TIALS como um campo extremamente novo e profícuo. Ainda são poucos os estudos voltados a esse tema, que carece de pesquisas para compreender não apenas a circulação da tradução entre os surdos, mas, especialmente, às formas de produção e recepção desse tipo de prática tradutória e interpretativa. Por essa razão, o estudo aqui apresentado aponta para temáticas importantes como a necessidade de estudos empírico-experimentais no contexto brasileiro para verificar o efeito dessas diferentes janelas junto ao público surdo a partir de rastreamento ocular, uma discussão sobre políticas linguísticas e de tradução para e no audiovisual e os efeitos desse debate no processo formativo de tradutores e intérpretes de Libras-português.

\section{Agradecimentos}

Agradeço à FAPESP pelo auxílio regular à pesquisa para a realização deste estudo e a equipe do LATRAVILIS/UFSCar, Anderson da Silva, Joyce de Souza, Rimar Segala, Rodrigo Fornari e Regina Torres, que participaram do processo de elaboração, tradução e revisão do questionário bilíngue.

Cad. Trad., Florianópolis, v. 41, $\mathbf{n}^{0}$ esp. 2, p. 163-201, ago/dez, 2021. 186 


\section{Referências}

ABNT. NBR 15.290 - Acessibilidade em comunicação na televisão. Rio de Janeiro: Associação Brasileira de Normas Técnicas, 2010. Disponível em: http:// www.crea-sc.org.br/portal/arquivosSGC/NBR\%2015290.pdf.

Albres, Neiva de Aquino. "Tradução em língua brasileira de sinais de texto informativo televisivo: reflexões sobre o processo”. Domínios de Lingu@Gem. V. 7 (2010): 131-150. Portal de Periódicos da UFU. 15/06/2019. http://www. seer.ufu.br/index.php/dominiosdelinguagem/article/view/11527/6807.

Ancine. Instrução Normativa N. 116, de 18 de dezembro de 2014. Dispõe sobre as normas gerais e critérios básicos de acessibilidade a serem observados por projetos audiovisuais financiados com recursos públicos federais geridos pela ANCINE; altera as Instruções Normativas $n .^{\circ} 22$, de 30 de dezembro de 2003, $n .^{\circ}$ 44, de 11 de novembro de $2005, n{ }^{\circ}$ 61, de 7 de maio de 2007 e $n .{ }^{\circ} 80$, de 20 de outubro de 2008, e dá outras providências. Disponível em: https://www.ancine. gov.br/pt-br/legislacao/instrucoes-normativas-consolidadas/instru-o-normativa-n116-de-18-de-dezembro-de-2014.

Ancine. Instrução Normativa N. 128, de 13 de setembro de 2016. Dispõe sobre as normas gerais e critérios básicos de acessibilidade visual e auditiva a serem observados nos segmentos de distribuição e exibição cinematográfica. Disponível em: https://www.ancine.gov.br/pt-br/legislacao/instrucoes-normativas-consolida das/instru-o-normativa-n-128-de-13-de-setembro-de-2016.

Angelim, Jonas; Nascimento, Vinícius, Tradução audiovisual da libras nas propagandas político-eleitorais de 2018: análise das janelas nas campanhas presidenciais no primeiro turno. Relatório de Pesquisa de Iniciação Científica. Departamento de Psicologia, Universidade Federal de São Carlos, São Carlos, 2020.

Bakhtin, Mikhail. Os gêneros do discurso. Tradução, posfácio e notas de Paulo Bezerra. São Paulo: Editora 34, 2016 (Impresso).

Bakhtin, Mikhail. Problemas da poética de Dostoievski. Trad. Paulo Bezerra. $5^{\text {a }}$. ed. Rio de Janeiro: Editora Forense, 2013 (Impresso). 
Bosh-Balliarda, Marta; Soler-Vilageliu, Olga; Orero, Pilar. "Sign Language interpreting on TV: a reception study of visual screen exploration in deaf signing users". MonTI. Monografias de Traduccion e Interpretación. 12 (2020): 108-143. 16/11/2021. E-revistes Universitat Jaume I. https://www.e-revistes.uji.es/index. $\mathrm{php} / \mathrm{monti} / \mathrm{article} / \mathrm{view} / 4452$.

Brait, Beth. "Olhar e ler: verbo-visualidade em perspectiva dialógica". Bakhtiniana, Revista de Estudos do Discurso, 2.8 (2013): 43-66. Scielo. 18/03/2017. http://www.scielo.br/pdf/bak/v8n2/04.pdf.

Brasil. Lei No 13.146, de 6 de julho de 2015. Institui a Lei Brasileira de Inclusão da Pessoa com Deficiência (Estatuto da Pessoa com Deficiência). Disponível em: http://www.planalto.gov.br/ccivil_03/_ato2015-2018/2015/lei/113146.htm.

Cardoso, Eduardo; Nogueira, Tiago Coimbra; Zardo, Kemi. "Investigando diferentes formatos para a tradução audiovisual em língua brasileira de sinais: uma pesquisa de preferências". (Anais) V Encontro Nacional de Acessibilidade Cultural, Rio de Janeiro, 2017. (Online). Disponível em: https://www.ufrgs.br/ comacesso/wp-content/uploads/2019/01/Resumo-ENAC-INVESTIGANDO.pdf.

Chaume, Frederic. "An overview of audiovisual translation: Four methodological turns in a mature discipline". Journal of Audiovisual Translation. 1.1 (2018): 4063. Open Journal Systems. 14/04/2020. http://www.jatjournal.org/index.php/jat/ article/view/43/3.

Deliza, Rosires.; Rosenthal, Amauri; Costa, Maria Cristina da. "Tradução e validação para a língua portuguesa de questionário utilizado em estudos do consumidor". Ciência e Tecnologia de Alimentos. 23.1. (2003): 43-48. Scielo. 31/07/2019. http://www.scielo.br/pdf/cta/v23n1/18253.pdf.

Gil, Antonio Carlos. Métodos e técnicas de pesquisa social. $7^{\text {a }}$ Ed. São Paulo: Atlas, 2019 (Impresso).

Greco, Gian Maria. "The nature of accessibility studies" Journal of Audiovisual Translation. 1.1. (2018): 205-232. Open Journal Systems. 14/04/2020. http:// www.jatjournal.org/index.php/jat/article/view/51/10. 
Minayo, Maria Cecilia de S.; Sanches, Odécio. "Quantitativo-Qualitativo: oposição ou complementaridade?" Cad. Saúde Pública. 3.9 (1993): 239-262. Scielo. 18/03/2017. http://www.scielo.br/pdf/csp/v9n3/02.pdf.

Moreira, Renata Lúcia. Uma descrição da dêixis de pessoa na língua de sinais brasileira: pronomes pessoais e verbos indicadores. (Dissertação de Mestrado). São Paulo: Universidade de São Paulo (USP), 2007.

Nascimento, Vinícius. "Janelas de Libras e gêneros do discurso: apontamentos para a formação e atuação de tradutores de língua de sinais." Trabalhos em Linguística Aplicada. 2.56. (2017): 461-492. Scielo. 15/03/2020 https://doi.org/ 10.1590/010318138649203273941.

Nascimento, Marcus Vinícius Batista. Formação de intérpretes de libras e língua portuguesa: encontros de sujeitos, discursos e saberes. (Tese de Doutorado). São Paulo: Pontifícia Universidade Católica de São Paulo (PUC-SP), 2016.

Nascimento, Marcus Vinícius Batista. Interpretação da língua brasileira de sinais a partir do gênero jornalístico televisivo: elementos verbo-visuais na produção de sentidos. Dissertação de Mestrado. São Paulo: Pontifícia Universidade Católica de São Paulo (PUC-SP), 2011.

Nascimento, Vinícius; Nascimento, Nicolas. "Interpretação do português para a Libras no Programa Roda Viva da TV Cultura: aspectos e estratégias do trabalho em equipe”. Revista (Con)textos linguísticos, 2021 [artigo aceito para publicação].

Nascimento, Vinícius; Fornari, Rodrigo Vecchio, Segala, Rimar Ramalho. "Tradução e pesquisa: o uso de questionário bilíngue para o mapeamento da usabilidade e preferência de janelas de libras na comunidade surda". Gragoatá. 49.24 (2019): 647-671. 14/04/2020. Portal de Periódicos da UFF. https:// periodicos.uff.br/gragoata/article/view/34092/22237.

Nascimento, Vinícius; Nogueira, Tiago Coimbra. "Tradução Audiovisual e o Direito à Cultura: O Caso da Comunidade Surda”. PERcursos Linguísticos. 21. 9. (2019): 105-132. Portal de Periódicos da UFES. 14/04/2020. http://www. periodicos.ufes.br/percursos/article/view/23740. 
Nascimento, Vinícius. "Consumo da cultura audiovisual por surdos: perfil sociolinguístico e questões para planejamento de políticas linguísticas e de tradução". Travessias Interativas. 22.10. (2020): 386-406. Portal de Periódicos da UFS. 13/10/2021. https://seer.ufs.br/index.php/Travessias/article/view/15345.

Nascimento, Vinícius. Presença da tradução e da interpretação das línguas de sinais no "grande tempo" da cultura. Bakhtiniana, Rev. Estud. Discurso. V.13, N. 3 (2018): 5-15. Scielo. 14/04/2019. http://www.scielo.br/pdf/bak/v13n3/21764573-bak-13-03-0005.pdf.

Nascimento, Vinícius. "Da norma legislativa à atividade interpretativa: acessibilidade comunicacional de surdos à mídia televisiva”. Diálogos em estudos da tradução e interpretação de língua de sinais. Editado por Anderson Almeida da Silva, Neiva de Aquino Albres e Angela Russo. Curitiba: Editora Prismas, 2016b, p 37-74. (Impresso)

Nascimento, Vinícius. "Gêneros do discurso e verbo-visualidade: dimensões da linguagem para a formação de tradutores/intérpretes de Libras/Português". Dialogismo: teoria e $(\mathrm{m})$ prática. Editado por Beth Brait e Anderson Salvaterra Magalhães. São Paulo: Terracota, 2014, p. 213-233. (Impresso).

Naves, Sylvia Bahiense; Mauch, Carla; Alves, Soraya Ferreira; Araújo, Vera Lúcia Santiago (Orgs). Guia para produções audiovisuais acessíveis. Brasília: Secretaria do Audiovisual do Ministério da Cultura, 2016 (Impresso).

Novaes, Herberth K. Janela de Libras: a avaliação de surdos, ouvintes que sabem e não sabem Libras (Trabalho de Conclusão de Curso). Instituto Superior de Educação de São Paulo - Singularidades, São Paulo, 2018 (Impresso).

Nogueira, Tiago; Alves, Tom Min. "Procedimentos e desafios na tradução de curtas-metragens para libras". Textos e contextos artísticos e literários: tradução e interpretação em libras: volume I. Editado por Natalia Schleder Rigo. Petrópolis: Editora Arara Azul, 2019, pp. 254-285.

Quadros, Ronice Muller.; Segala, Rimar Ramalho. Tradução intermodal, intersemiótica e interlinguística de textos escritos em português para a libras oral. Cadernos de Tradução. V. 35, N. 2 (2015): 354-386. Portal de periódicos da UFSC.

Cad. Trad., Florianópolis, v. 41, $\mathbf{n}^{0}$ esp. 2, p. 163-201, ago/dez, 2021. 190 
Rodrigues, Carlos Henrique. A interpretação para a língua de sinais brasileira: efeitos de modalidade e processos inferenciais. (Tese de Doutorado). Belo Horizonte: Universidade Federal de Minas Gerais (UFMG), 2013.

Rodrigues, Carlos Henrique; Santos, Silvana Aguiar. A interpretação e a tradução de/para línguas de sinais: contextos de serviços públicos e suas demandas. Tradução em Revista. V. 24, N. 12 (2018): 1-29. Maxwell-PUC-Rio. 02/03/2019. https://www.maxwell.vrac.puc-rio.br/34535/34535.PDF.

Rodrigues, Carlos Henrique. "Interpretação simultânea intermodal: sobreposição, performance corporal-visual e direcionalidade inversa". Revista da ANPOLL. 44.1 (2018): 111-129. Portal da ANPOLL. 04/06/2019. https://revistadaanpoll. emnuvens.com.br/revista/article/view/111/940.

Romero-Fresco, Pablo. "In support of a wide notion of media accessibility: Access to content and access to creation". Journal of Audiovisual Translation. 1.1. (2018): 187-204. Open Journal Systems. 14/04/2020. http://www.jatjournal. org/index.php/jat/article/view/53/12.

Segala, Rimar Ramalho. Tradução intermodal e intersemiótica/interlinguística: português escrito para a língua de sinais. (Dissertação de Mestrado) Florianópolis: Universidade Federal de Santa Catarina (UFSC), 2010.

Schmidt, Felipe. "Pessoas com deficiência: breves notas sobre sua terminologia, seu conceito jurídico e sua disciplina constitucional no Brasil". Revista Jurídica do MPE-TO. 17. (2019): 142-157 Portal do Ministério Pùblico Estadual de Tocantins. 13/10/2021. http://cesaf.mpto.mp.br/revista/index.php/revistampto/ article/view/14/3.

Silva, Karen Fernanda Bianchini da. Tradução audiovisual da língua de sinais: aspectos emocionais, formação e condição de trabalho. Trabalho de Conclusão de Curso. Florianópolis, Universidade Federal de Santa Catarina (UFSC), 2015. Disponível em: https://repositorio.ufsc.br/handle/123456789/161436.

Tuominen, Tiina. "Multi-method research: reception in context". Reception studies and audiovisual translation. Editado por Elena Di Giovani e Yves Gambier. Amsterdam/Philadelphia: John Benjamins Publishing Company, 2018, pp. 69-90.

Cad. Trad., Florianópolis, v. 41, $\mathrm{n}^{0}$ esp. 2, p. 163-201, ago/dez, 2021.191 
Volochínov, Valentin Marxismo e filosofia da linguagem: problemas fundamentais do método sociológico na ciência da linguagem. Tradução de Sheila Grillo e Ekaterina Vólkova Américo. São Paulo: Editora 34, 2017.

Wehrmeyer, Jennifer. "Eye-Tracking Deaf and Hearing Viewing of Sign Language Interpreted News Broadcasts". Journal of Eye Movement Research, 7.1. (2014): 1-16, http://doi:10.16910/jemr.7.1.3.

Vinícius Nascimento. E-mail: nascimento_v@ufscar.br. https://orcid.org/00000003-3057-5828.

Cad. Trad., Florianópolis, v. 41, $\mathrm{n}^{0}$ esp. 2, p. 163-201, ago/dez, 2021. 192 


\section{ANEXO: QUESTIONÁRIO BILÍNGUE}

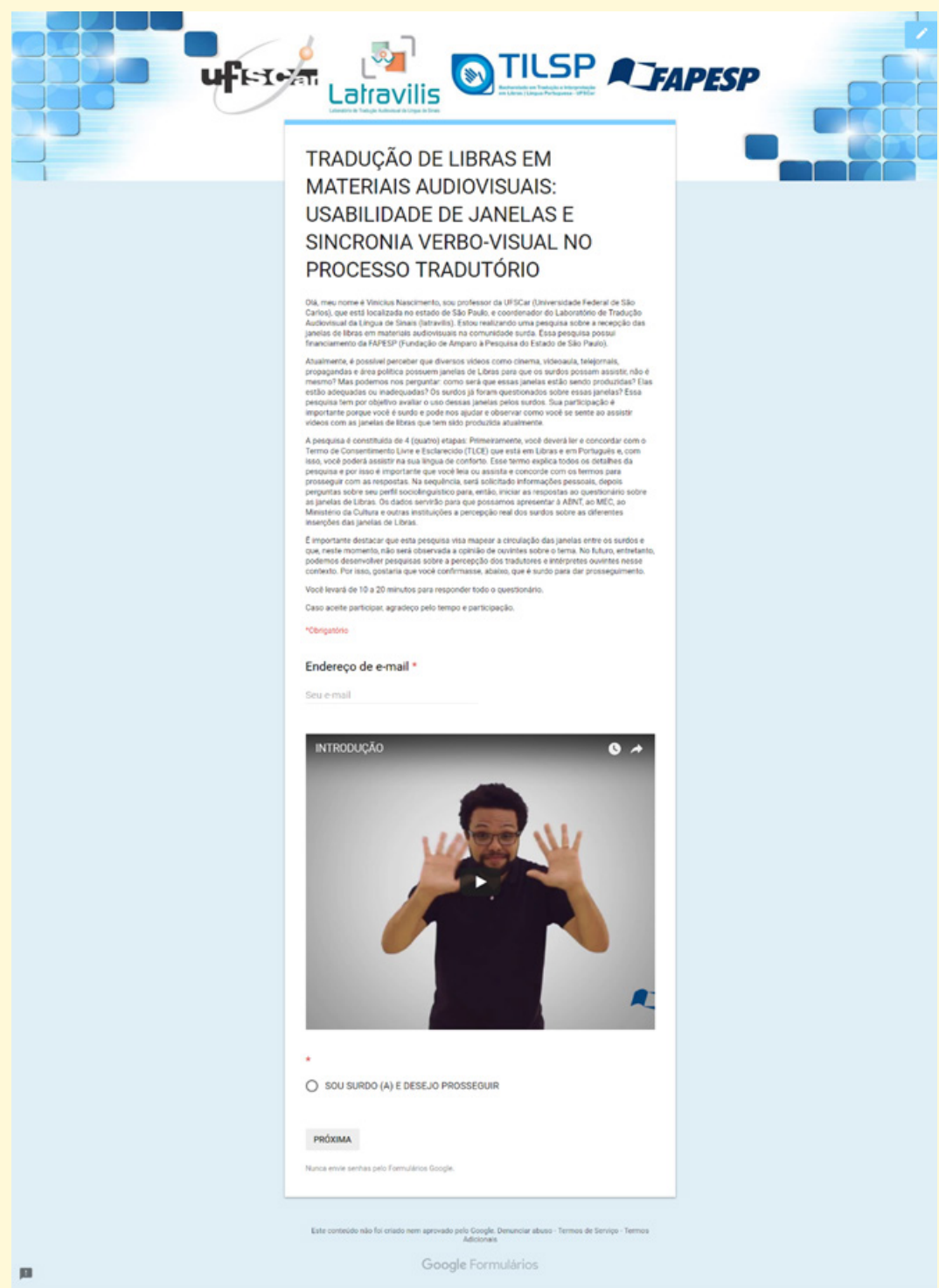

Cad. Trad., Florianópolis, v. 41, $\mathrm{n}^{0}$ esp. 2, p. 163-201, ago/dez, 2021. 193 


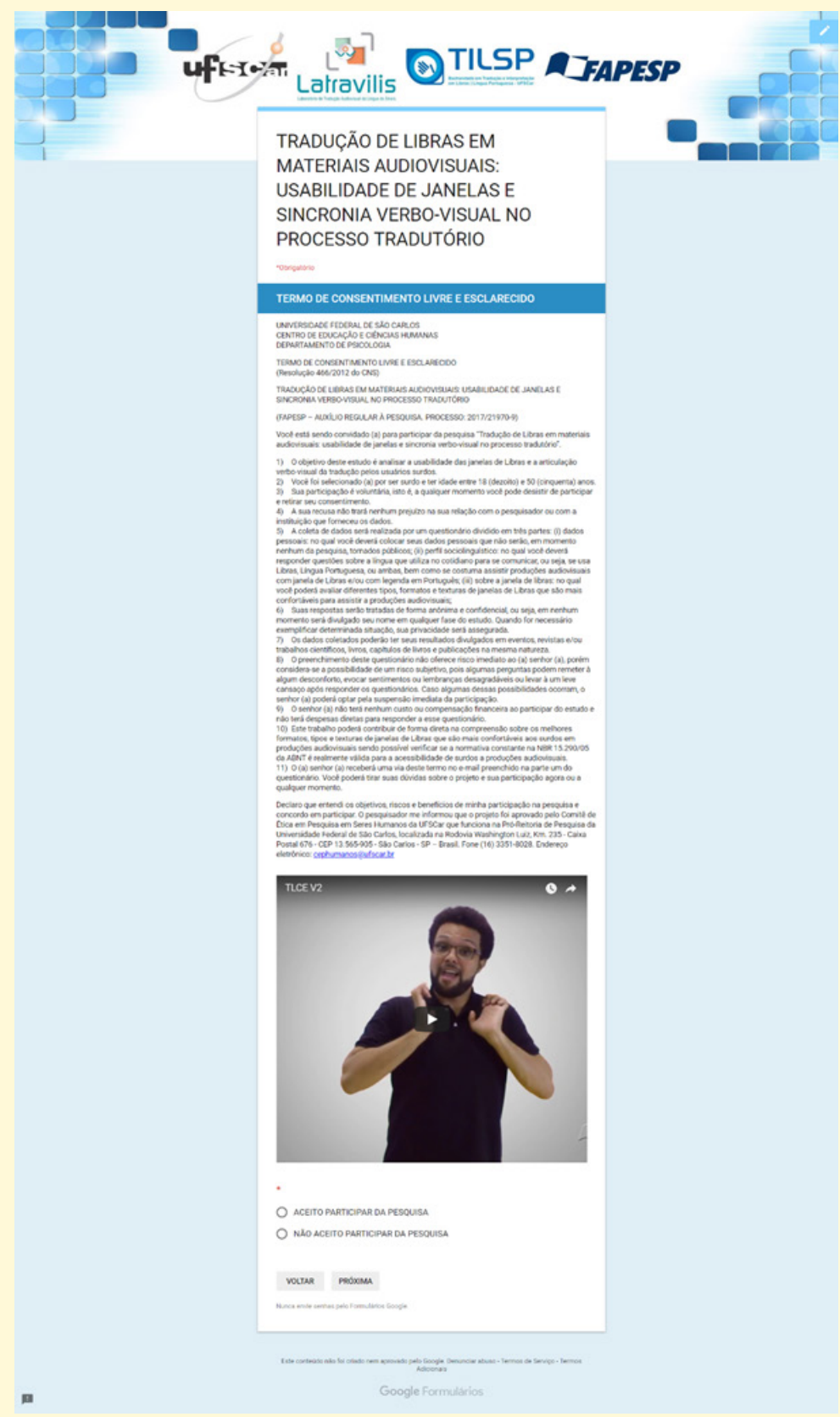

Cad. Trad., Florianópolis, v. 41, $\mathrm{n}^{0}$ esp. 2, p. 163-201, ago/dez, 2021. 194 


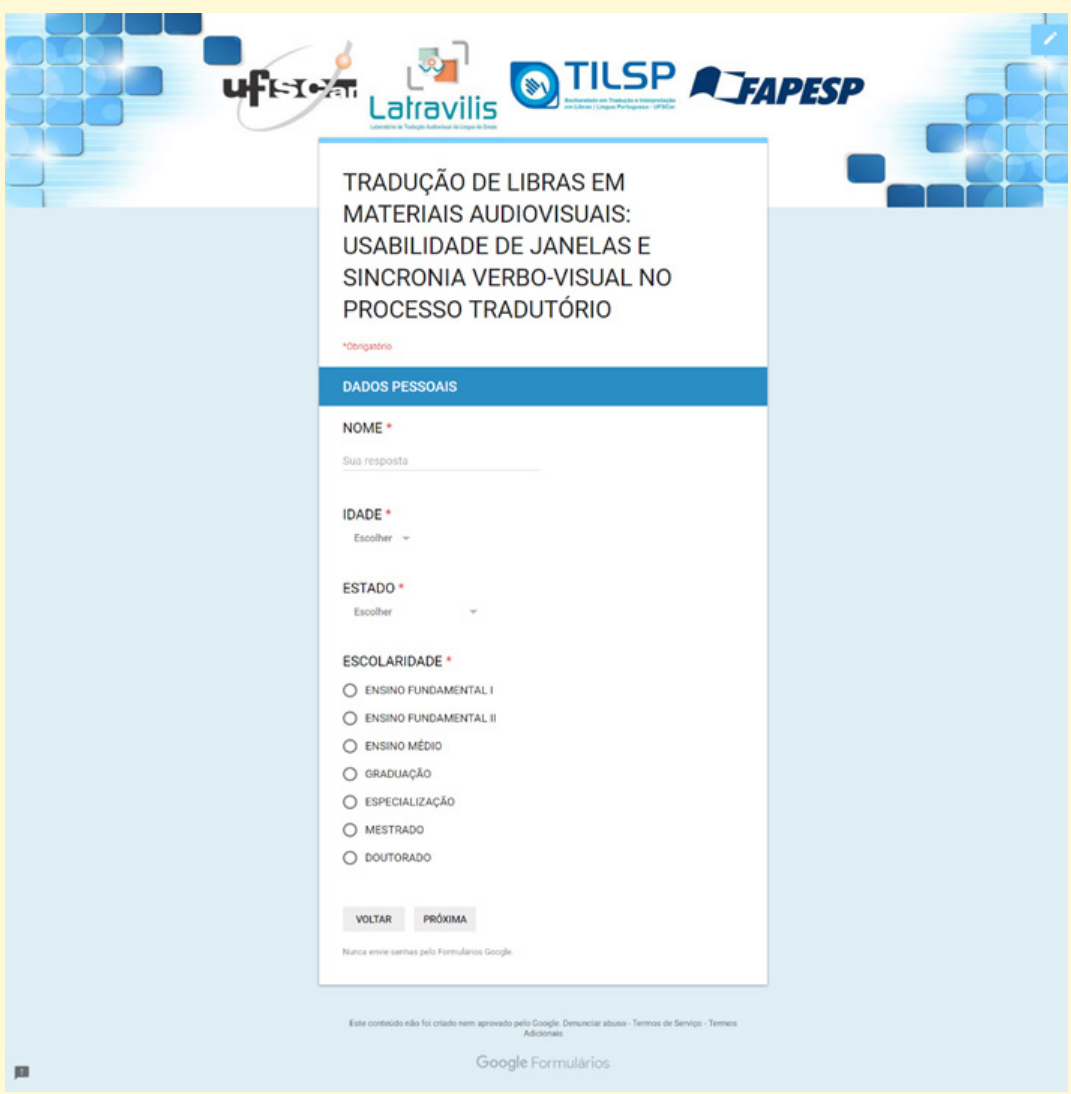

Cad. Trad., Florianópolis, v. 41, $n^{0}$ esp. 2, p. 163-201, ago/dez, 2021. 195 


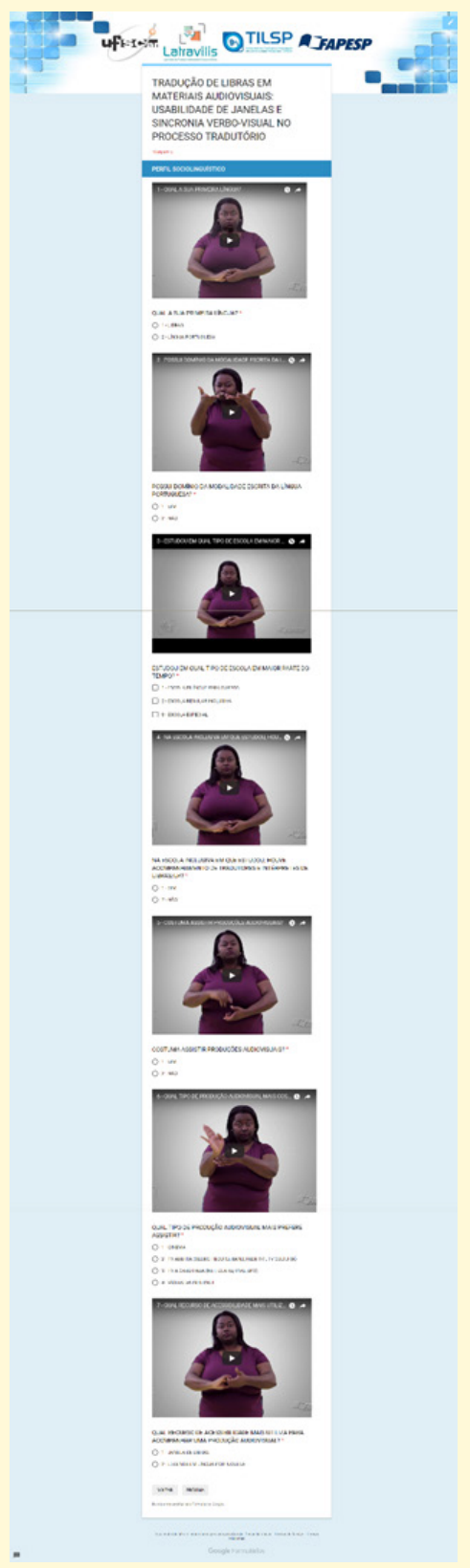

Cad. Trad., Florianópolis, v. 41, $\mathrm{n}^{0}$ esp. 2, p. 163-201, ago/dez, 2021. 196 


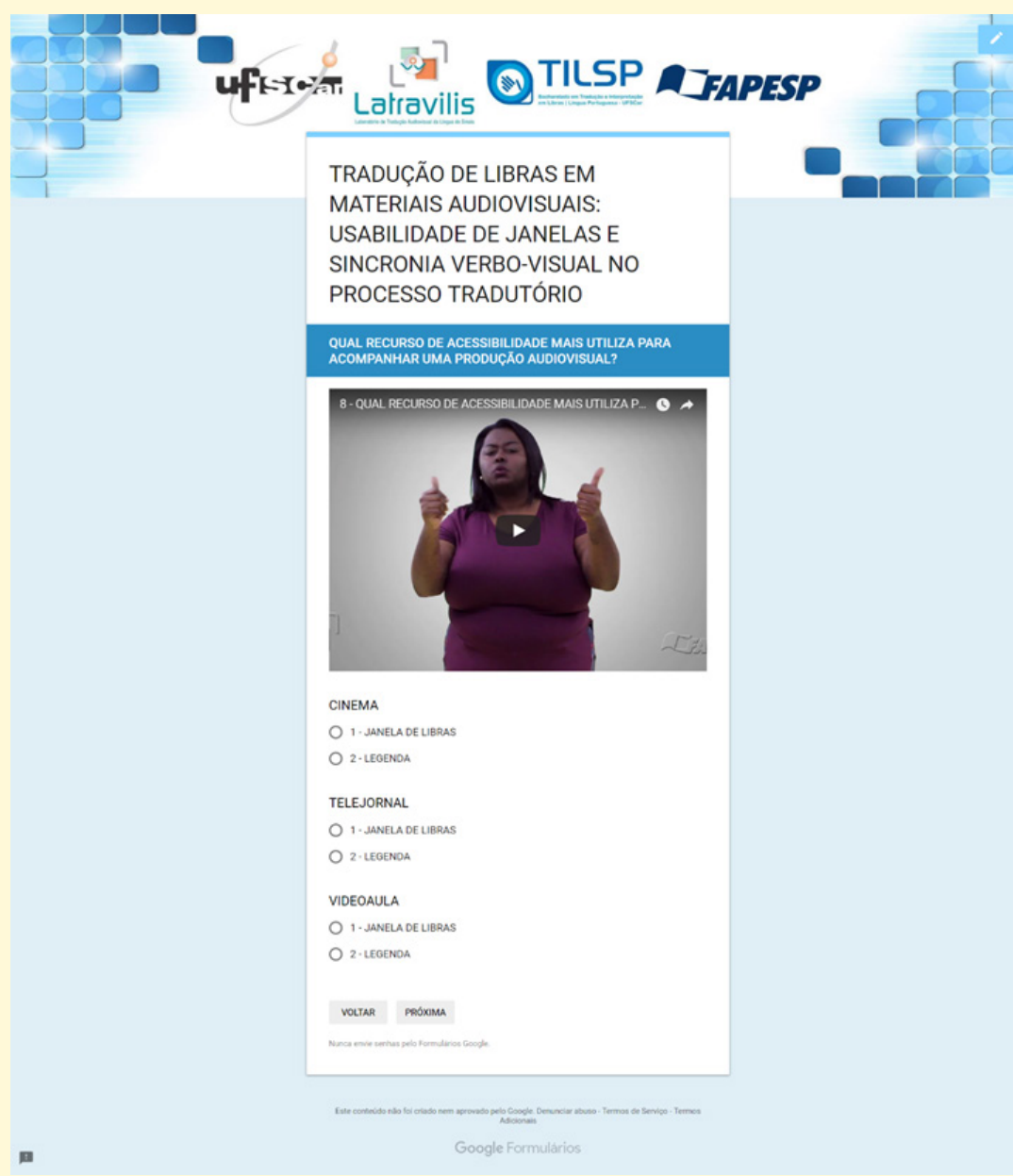

Cad. Trad., Florianópolis, v. 41, $\mathrm{n}^{0}$ esp. 2, p. 163-201, ago/dez, 2021. 197 


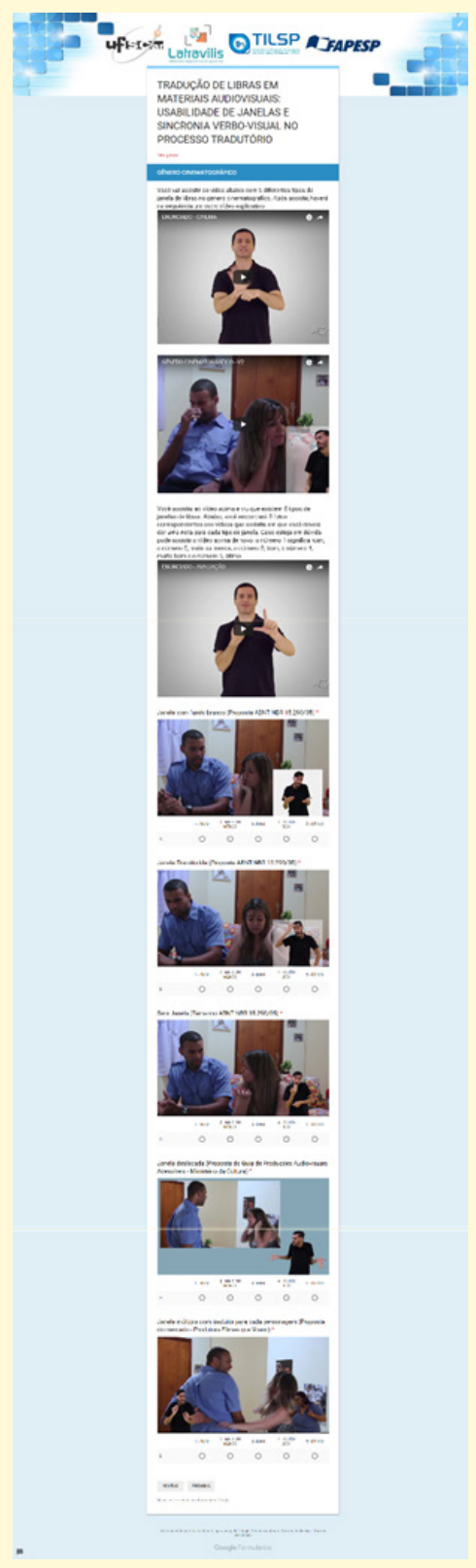

Cad. Trad., Florianópolis, v. 41, $\mathbf{n}^{0}$ esp. 2, p. 163-201, ago/dez, 2021. 198 


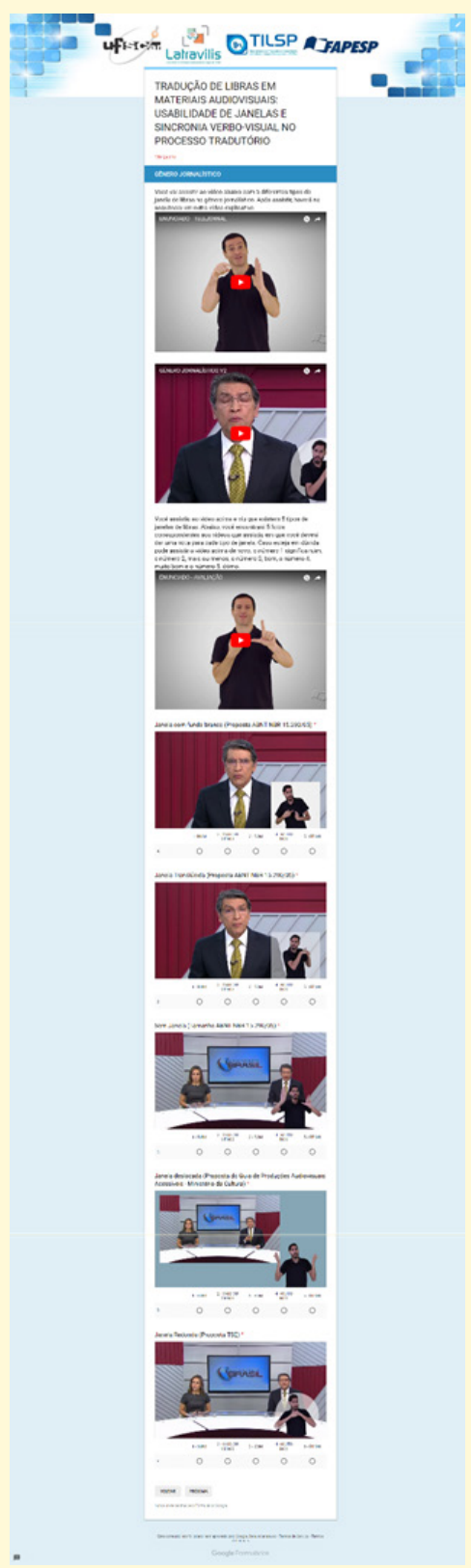

Cad. Trad., Florianópolis, v. 41, n $^{0}$ esp. 2, p. 163-201, ago/dez, 2021. 199 


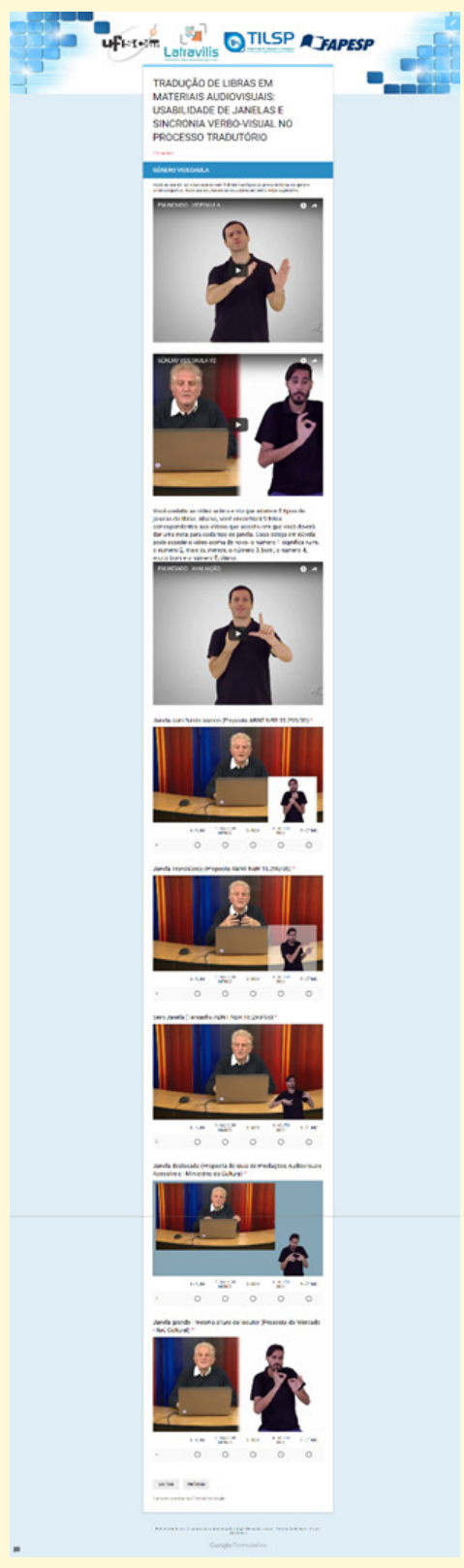

Cad. Trad., Florianópolis, v. 41, $\mathrm{n}^{0}$ esp. 2, p. 163-201, ago/dez, 2021. 200 


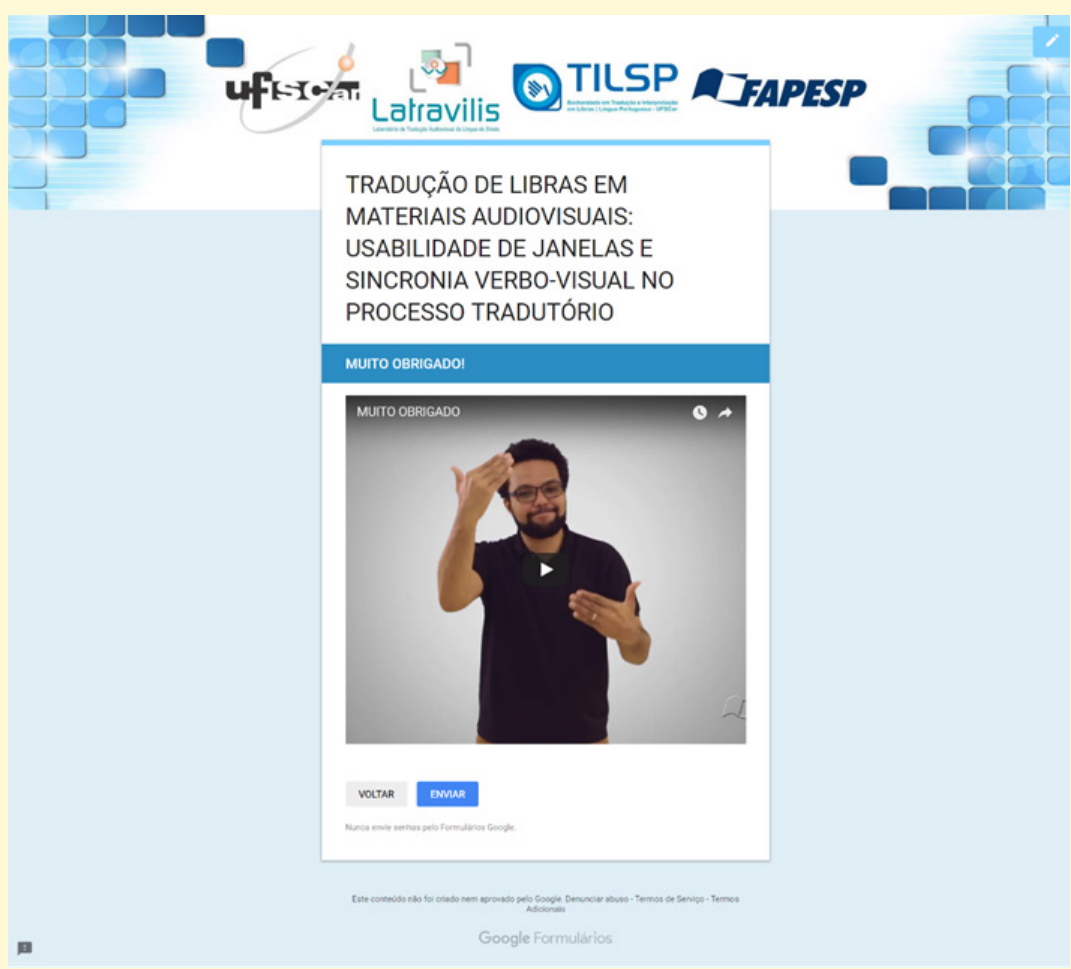

Cad. Trad., Florianópolis, v. 41, $\mathbf{n}^{0}$ esp. 2, p. 163-201, ago/dez, 2021. 201 